\title{
Should whole genome sequencing be performed in all newborns?
}

\section{Michael Shevell MD CM, FRCP, FCHAS}

Chair of Department of Pediatrics and Professor of Departments of Pediatrics and Neurology/ Neurosurgery, McGill University

Pediatrician-in-Chief, Montreal Children's Hospital-McGill University Health Centre

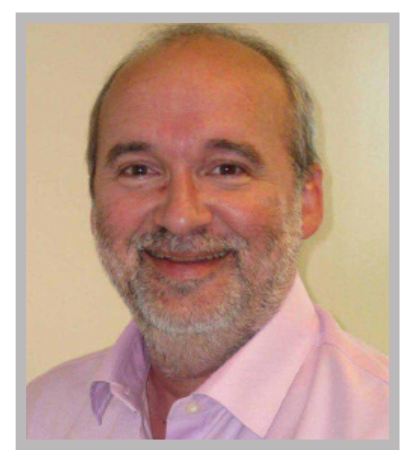

Circa 2015, the answer to this question in my opinion is an emphatic no. We are simply not ready for prime-time on this matter yet due to a multitude of reasons. Recent technological advances have enabled whole genome sequencing (WGS), and rapidly declining costs (the fabled $\$ 1000$ genome) have made it potentially feasible on a population-wide basis. Theoretically, WGS in newborns offers the possibility of achieving population-health gains as a byproduct of advances in genetic understanding and technology ${ }^{1}$. However, that something is doable does not necessarily entail that we should do so. There are enormous technical, ethical, legal and policy challenges which must be addressed prior to implementing universal neonatal WGS.

Newborn screening has been available for an everexpanding group of pre-symptomatically diagnosable and treatable genetically determined disorders for slightly more than 50 years ${ }^{2}$. It has been formulated and implemented as a public-health measure, applied universally on a population-wide basis without the needed consent of participants. There is no doubt that it has saved many lives and reduced morbidity, making possible for thousands of individuals a life of 'normality' as opposed to often frequent devastating neurodevelopmental disability that renders an individual dependent rather than autonomous. Wilson and Jungner in $1968^{3}$ elaborated in a seminal and highly influential publication the criteria for population screening for a disorder (Table 1). These have stood the test of time and remain the gold-standard for evaluation as new disorders are added to those screened in newborns. Special emphasis should be placed on criteria \#2 and \#3.

The mechanics of testing is but one aspect of newborn screening. An enormous network of infrastructure and human resources are additionally necessary for education, counselling, treatment (where possible) and programmatic follow up (criteria \#3) ${ }^{4}$. WGS will offer the possibility of diagnosing more than
Table 1: Wilson and Jungner Screening Criteria (Adapted from Andermann et al. ${ }^{1}$

1. The condition sought should be an important health problem

2. There should be an accepted treatment for patients with recognized disease

3. Facilities for diagnosis and treatment should be available

4. There should be a recognizable latent or early symptomatic phase

5. There should be a suitable test or examination

6. The test should be acceptable to the population

7. The natural history of the condition, including development from latent to declared disease, should be adequately understood

8. There should be an agreed policy on whom to test as patients

9. The cost of case-finding (including diagnosis and treatment of patients diagnosed) should be economically balanced in relation to possible expenditure on medical care as a whole

10. Case-finding should be a continuing process and not a "once and for all" project

3000 genetic disorders and elucidating variants in an ever-expanding multitude of other genes that confer not disease, but an increased risk for a disorder. Less than 100 of these disorders are treatable presently in a manner analogous to the substantial treatment effects conferred by interventions for those disorders now screened for (criteria \#2). Furthermore, many of these disorders have an onset decades removed from infancy. Thus for the vast majority of diseases to be diagnosed by WGS, only the time of diagnosis will be advanced leaving health outcome ultimately unaffected. Thus no measurable populationhealth gain is achieved. Rather what is created is an enormous additional demand on an already over-burdened public health care system as individuals and families seek counselling, education and risk management information for which we have little in the way of present objective evidence or help to offer ${ }^{5}$.

Newborn WGS would result in the generation of substantial 
amounts of data, which would need to be stored while respecting privacy concerns and incorporated into the individual's health record. The potential impact of incidental findings (for example mistaken paternity assumptions) and their use in future employment and insurance matters are enormous and have yet to be carefully considered by society $^{6}$. What is desperately needed is a careful, detailed, wide-ranging and objective assessment of the impacts foreseen for newborn WGS. Fortunately, the American National Institutes of Health in 2013 has directed $\$ 25$ million for prospective studies in WGS best practices under their Genomic Sequencing and Newborn Screening Disorders program $^{2}$. To provide a Canadian context to the discussion, the Canadian Institute for Health Research (CIHR) and $\mathrm{ClHR}$ and Social Sciences and Humanities Research Council (SSHRC) granting agencies should undertake a similar commitment. This will then need to be followed by a broad public discussion of these matters holding at its pinnacle the following key question: What is in the best interests of the screened newborn? ${ }^{4}$

Only once this data becomes available and an ensuing informed public discussion has taken place, may we be ready for 'prime-time' with reference to newborn WGS.

\section{References}

1. Andermann A, Blancquaert I, Beauchamp S, Dery V. Revisiting Wilson and Jungner in the genomic era: A review of screening criteria over the past 40 years. Bull WHO 86: 2008.

2. Meade C, Bonhomme NF. Newborn screening: Adapting to advancements in whole-genome sequencing. Genetic Test Mol Biomark 18:597-598, 2014.

3. Wilson JMG, Jungner J. Principles and Practice of Screening for Disease. WHO (Geneva): 1968.

4. Knoppers BM, Senecal K, Borry P, Avard D. Whole-genome sequencing in newborn screening programs. Sci Trans Med 26:229, 2014

5. Ulm E, Feero WG, Dineen R, Charrow J, Wicklund C. Genetics'professionals' opinions of whole-genome sequencing in the newborn period. J Genet Couns [Epub ahead of print] Oct 28, 2014.

6. ACMG. Incidental findings in clinical genomics:A clarification. Gent Med 8:664-666, 2013.

\section{Michael Shevell MD CM, FRCP, FCHAS}

Michael Shevell is a pediatric neurologist who is presently Chair of the Department of Pediatrics at McGill University and Pediatrician-in-Chief of the Montreal Children's Hospital. His research has focused on the causes, care and consequences of infants and children either at-risk for, or with, neurodevelopmental disabilities such as global developmental delay, intellectual disability and cerebral palsy. In 2014, he was granted Fellowship in the Canadian Academy of Health Sciences and awarded the Hower Award by the Child Neurology Society. 